\title{
Monomorphic Ventricular Tachycardia by ECG Finding
}

National Cancer Institute

\section{Source}

National Cancer Institute. Monomorphic Ventricular Tachycardia by ECG Finding. NCI

Thesaurus. Code C62234.

An electrocardiographic finding of a ventricular tachycardia in which the QRS complexes

have a uniform morphology. (CDISC) 